\title{
BMJ Open Influence of information provided prior to switching from Humira to biosimilar adalimumab on UK patients' satisfaction: a cross-sectional survey by patient organisations
}

\author{
Kayoko Kaneko, ${ }^{1}$ Daniel Prieto-Alhambra (1D , ${ }^{2}$ Clare Jacklin, ${ }^{3}$ Ailsa Bosworth, ${ }^{3}$ \\ Sally Dickinson, ${ }^{4}$ Sarah Berry, ${ }^{5}$ Helen McAteer, ${ }^{6}$ Peter C Taylor (D) ${ }^{1}$
}

To cite: Kaneko K, PrietoAlhambra D, Jacklin C, et al. Influence of information provided prior to switching from Humira to biosimilar adalimumab on UK patients' satisfaction: a crosssectional survey by patient organisations. BMJ Open 2022;12:e050949. doi:10.1136/ bmjopen-2021-050949

- Prepublication history and additional supplemental material for this paper are available online. To view these files, please visit the journal online (http://dx.doi.org/10.1136/ bmjopen-2021-050949).

Received 10 March 2021 Accepted 28 January 2022

Check for updates

(C) Author(s) (or their employer(s)) 2022. Re-use permitted under CC BY-NC. No commercial re-use. See rights and permissions. Published by BMJ.

For numbered affiliations see end of article.

Correspondence to Professor Peter C Taylor; peter.taylor@kennedy.ox.ac.uk

\section{ABSTRACT}

Objectives To investigate the perceptions and experiences of people with specific immune-mediated inflammatory diseases during the process of switching from Humira to biosimilar adalimumab.

Design Cross-sectional survey.

Setting An anonymised, self-administered, web-based survey.

Participants The participants were drawn from members and non-members of either the National Rheumatoid Arthritis Society, the National Axial Spondyloarthritis Society, Crohn's and Colitis UK, or Psoriasis Association. Birdshot Uveitis Society and Olivia's Vision also signposted to the survey links.

Results A total of 899 people living with various immune mediated inflammatory diseases participated in this survey. Thirty-four per cent of respondents reported poor overall satisfaction with their biosimilar adalimumab after the switch, associated with complaints related to the switching process including lack of shared decision making, scarcity of information provided by or signposted to by the department instigating the switch as well as lack of training with the new injection device. Where training with the new device had been provided, there were significantly reduced reports of pain when injecting the new biosimilar (OR $0.20,95 \% \mathrm{Cl} 0.07$ to 0.55 ), side effects (OR $0.17,95 \% \mathrm{Cl} 0.06$ to 0.47 ) and difficulty in using the new injection device (OR $0.25,95 \% \mathrm{Cl} 0.15$ to 0.41 ). Self-reported side effects were reduced by (OR $0.13,95 \% \mathrm{Cl} 0.05$ to 0.38 ) when written information was provided by healthcare professionals and by (OR 0.15 , $95 \% \mathrm{Cl} 0.05$ to 0.42 ) with provision of verbal information. Difficulty in using the new injection device was also reduced by provision of satisfactory information such as written documents (OR $0.38,95 \% \mathrm{Cl} 0.23$ to 0.63 ) or by verbal communication with healthcare professionals (OR $0.45,95 \% \mathrm{Cl} 0.27$ to 0.73 ). Finally, provision of satisfactory written or verbal information was associated with a reduction in any negative perception regarding symptom control with the new biosimilar by (OR $0.05,95 \%$ $\mathrm{Cl} 0.004$ to 0.57 ) and by (OR $0.15,95 \% \mathrm{Cl} 0.03$ to 0.84 ), respectively.
Strengths and limitations of this study

- This was an anonymised, self-administered, webbased survey designed by members of patient organisations for the purposes of service evaluation following a switch from originator to biosimilar adalimumab.

- Survey questions were designed to investigate the patients' experience of the switching process.

- Face validity of the survey questions was established by asking members of the relevant patient organisations to read through the questions and check them for sense and relevance.

- The study design included an open invitation to participate in the survey which may have had the limitation of introducing selection bias among respondents.

- Another limitation of the survey is that it was not designed or powered to assess any influence of the biological formulation on the switching experience.

Conclusions Patient reported experiences of the process of switching from originator to biosimilar emphasise the importance of clear communication, training and information in order to optimise perception and maximise achievable outcomes with the new treatment.

\section{INTRODUCTION}

Over the last two decades, biological tumour necrosis factor (TNF) inhibitors such as adalimumab (ADA) have transformed achievable outcomes for patients with a wide variety of immune mediated inflammatory diseases including rheumatoid arthritis (RA), axial spondyloarthropathies (AS), skin psoriasis and psoriatic arthritis (PsA), Crohn's disease (CD) and other inflammatory bowel diseases such as ulcerative colitis (UC). However, the very high acquisition costs have resulted in varying degrees of restricted access across 
global healthcare economies. In 2017/2018, ADA cost the National Health Service (NHS) in England $£ 462 \mathrm{~m}$, of which $£ 436 \mathrm{~m}$ was spent on the drug's use in hospitals. In Scotland, the spend was in excess of $£ 40 \mathrm{~m}$ per annum, and in Wales, ADA cost secondary care $£ 15 \mathrm{~m}$ in 2016/2017. ${ }^{1}$ When originator drugs approached patent expiry, biosimilar drugs emerged, and several have been approved for use in Europe. The first to be approved were infliximab and etanercept biosimilars, and more recently ADA biosimilars. A commissioning framework for use of best value biological medicines (including biosimilar medicines) was published by NHS England in September 2017, setting out NHS England's position and providing a framework to help commissioners develop plans for rapid and effective uptake of the best value biological medicines. ${ }^{2}$ In September 2018, NHS England published their commissioning intentions for ADA following the loss of patent exclusivity for Humira. ${ }^{3}$ Guidance was issued to NHS Trusts and clinical commissioning groups with instructions that 9 out of 10 new patients should be started on the best value biologic medicine within 3 months of a biosimilar launch and that at least $80 \%$ of existing patients should be switched or remain on the best value biologic (which could be the originator or a biosimilar) within 12 months. These directives came with the expectation of at least $£ 150$ million savings per year by 2021 . The National Rheumatoid Arthritis Society (NRAS), National Axial Spondyloarthritis Society (NASS), Crohn's \& Colitis UK (CCUK), and the Psoriasis Association together welcomed the news. In a joint statement, they said: 'We welcome increased availability of effective treatment options for patients and understand the importance of the wise and careful use of NHS resources. The introduction of biosimilars for ADA brings opportunities for both patients and the NHS. However, it is vital that patients are fully informed about all the treatment options available to them and commissioners and health professionals adopt the principles of shared decision making.'

Although some previous studies have investigated the knowledge and perception of biosimilars among patients who had not yet switched to biosimilars from originators, ${ }^{45}$ the satisfaction and perception of the switching process among patients who have already experienced it remains unclear. For people living with an immune mediated inflammatory disease whose disease has been well-controlled on a biologic anti-TNF originator, having to switch to an alternative agent may cause anxiety and even suspicion, especially if it is known that the reason for switching is to save money. ${ }^{6}$ Therefore, it might be anticipated that provision of appropriate reassurance and relevant information during the switching process will have a substantial influence on achieving optimum outcomes and benefits.

In the present manuscript, we report the findings of a web-based survey designed by four UK patient organisations for people living with immune mediated inflammatory diseases for which biologic TNF inhibitors may be indicated, NRAS, NASS, CCUK and the Psoriasis
Association UK. The survey was conducted in the UK to investigate the perceptions and experiences of patients about the process of switching from Humira to biosimilar ADA after the switch had been made.

\section{METHODS}

\section{Study design, setting and population}

This was an anonymised, self-administered, web-based survey among patients who interacted with the following patient organisations; NRAS, NASS, CCUK or Psoriasis Association UK. In addition, the Birdshot Uveitis Society and Olivia's Vision also signposted to the survey links. The survey was undertaken for the purposes of service evaluation, prompted by the statement in NHS England's biosimilar commissioning framework that 'shared decision making between clinical prescribers and patients will be vital if the best value, clinically effective medicines are to be used'. ${ }^{2}$ The data were collected and analysed anonymously in subjects following a switch from originator to biosimilar ADA. The survey questions were designed to investigate the patients' experience of the switching process. Survey questions were developed by members of the patient organisations based on issues determined to be of importance to patients. Face validity of the questions formulated was established by asking members of the relevant patient organisations to read through the questions and check them for sense and relevance.

The online survey was promoted via social media platforms, online communities and through the organisations' membership communications platforms. The patients were asked to complete the survey once they had completed the switching processes. People who lived outside the UK or were aged under 18 were excluded. This survey was designed by the four patient organisations and then distributed between 4 April 2019 and 30 November 2019. The survey front page included information describing the survey and asked participants for voluntary participation. An electronic consent of voluntary participation was sought from the respondents by clicking an 'agree' button. All the responders were able to review and change their responses by scrolling up and down the page before submission. Cookies were used by the survey tool to minimise the chance of more than one response per computer.

A questionnaire comprising 27 questions was hosted on an electronic survey platform (Survey Monkey) and divided into three parts in the following manner: (1) characteristics of participants (questions 1-9, 26, 27), (2) individual experience of the switching process and perception of the new biosimilar (questions 10-23), (3) individual opinion related to the switching process (questions 24, 25 ), (see survey questions in online supplemental material). Most questions were formulated as closed, multiplechoice questions (MCQs), combined with free comments, with the exception of questions 13, 24, 25 which were full open questions. Findings from the free comments and open questions were not formally analysed as a part of 
the present work. The questionnaire did not ask for any personal identifying information. All the survey questions were developed to explore individual participants' perceptions and satisfaction with the switching process from ADA originator to a biosimilar product.

To explore the factors identified by the survey respondents which contributed to their perceptions of the switching process, we grouped them based on the level of satisfaction with the services provided by their healthcare providers before switching, such as written information, verbal information and training for the new devices. Participants answering '4 (somewhat satisfied)' or '5 (very satisfied)' in question 12 were assigned to a category designated as 'satisfied' and those responding that they were ' 1 (not at all satisfied)' or '2 (somewhat dissatisfied)' were assigned to a category of 'dissatisfied'. Participants responding as '3 (neither)' or 'not applicable (N/A)' were excluded from these categories. With respect to the participants' perceptions of efficacy of the biosimilar, patients who answered 'slightly better' and 'much better' in questions 15 to 18 were assigned to a category of 'better perception' and those who answered 'slightly worse' and 'much worse' were assigned to a category of 'worse perception'. Those participants responding that the efficacy of the biosimilar was 'the same' as originator or 'not applicable (N/A)' were excluded from these categories.

\section{Patient and public involvement}

The survey questions were designed by members of the four national patient organisations and the survey itself was hosted on the websites of each of the four patient organisations. Members of the organisations and nonmembers visiting the website were invited to participate in the survey. Members of the four organisations made data available to the corresponding author, who is chief medical advisor to NRAS, and his colleagues for analysis. Members of the patient organisations have commented on the findings, contributed to writing and have approved the final version of this manuscript.

\section{Statistical analyses}

The survey responses to the closed questions formulated as MCQs were collected and presented as number and percentages of responding patients. Variables were based on the choices of MCQ options. Disease activity was selfreported by the participants in question 9. Comparison of frequency of responses which showed 'better' or 'worse perception' between 'the satisfied group' and 'the dissatisfied group' were expressed as OR and $95 \%$ CI. P values were assigned based on the $\chi^{2}$ test for categorical values when their expected values were higher than 10 and Fisher's exact test was conducted if expected values of categorical values were smaller than with 10 . P values less than 0.05 was considered statistically significant. A multiple categorical logistic regression analysis was used to select factors significantly associated with a positive perception of the new biosimilars following the switching process, after adjusting for gender, self-reported disease activity and biosimilar brands. All analyses were performed in JMP V.14.0 for windows.

\section{RESULTS}

\section{Participants}

A total of 899 patients with different immune mediated inflammatory diseases participated in this survey. The largest response came from patients with CD (42\%) followed by RA/juvenile idiopathic arthritis (25\%), AS $(19 \%)$ and skin psoriasis and PsA (13\%). Most of the participants $(52 \%)$ had been taking Humira for between 1 and 5 years; about one-fifth were recent users $(<1 \mathrm{y})$ and almost one-fifth were long-term users ( $>5$ years). By self-evaluation of disease activity prior to switch, the majority (62\%) were very well controlled, and $26 \%$ well controlled. Ten per cent of participants had undertaken the survey just after their first injection of the new biosimilar (table 1).

\section{The patients' experience and satisfaction with experience of switching process}

Concerns about switching had been shared with the healthcare team by $43 \%$ of respondents and about a third of these ( $16 \%$ of all survey participants) did not have their concerns satisfactorily dealt with. Over half of respondents (53\%) reported not being asked for consent before switching and the majority of respondents reported poor overall satisfaction with their biosimilar ADA after the switch with only $8 \%$ 'very satisfied', while $34 \%$ were 'not at all satisfied' (table 2).

Sixteen per cent of participants were not at all satisfied with the written information about the switch to a biosimilar and $23 \%$ were dissatisfied with the verbal information received from their healthcare professionals. The lack of training with the new injection device was also highlighted by $21 \%$ of respondents. Furthermore, more than half reported that they were not given an option to decline the switch or to delay it but rather to remain on originator $(56 \%$ and $52 \%$, respectively) (figure 1).

After switching from originator to biosimilar, the most commonly reported problem was that of 'worse pain' on injection with the biosimilar compared with originator. The injection pain was said to be 'much worse' by $51 \%$ and 'slightly worse' by $23 \%$ (figure 1). Ease of using the injection device was reported to be much worse by $22 \%$ of respondents. With respect to symptom control after the switch, $47 \%$ reported it to be the same or better $(2 \%)$ than with originator. However, 20\% reported that their symptoms were 'much worse' (figure 1). Respondents rating themselves as having higher disease activity tended to report greater dissatisfaction with all aspects of the switching process including written information, verbal information and training on the new injection devices (online supplemental table S1). 
Table 1 Participant baseline characteristics

\begin{tabular}{|c|c|}
\hline Characteristics & $\begin{array}{l}\text { Participants } \\
(\mathrm{n}=899)\end{array}$ \\
\hline \multicolumn{2}{|l|}{ Gender, $\mathrm{n}(\%)$} \\
\hline Female & $609(68)$ \\
\hline Male & $277(31)$ \\
\hline Prefer not to say & $6(0.7)$ \\
\hline Missing & $7(0.8)$ \\
\hline \multicolumn{2}{|l|}{ Age, $n(\%)$} \\
\hline $18-24$ & $76(8)$ \\
\hline $25-44$ & $323(36)$ \\
\hline $45-64$ & $375(42)$ \\
\hline $65+$ & $118(13)$ \\
\hline Prefer not to say & $7(0.8)$ \\
\hline \multicolumn{2}{|l|}{ Medical conditions, $\mathrm{n}(\%)$} \\
\hline Crohn's disease and ulcerative colitis & $376(42)$ \\
\hline Rheumatoid arthritis and juvenile idiopathic arthritis & $227(25)$ \\
\hline Axial spondyloarthritis including ankylosing spondylitis & $170(19)$ \\
\hline Skin psoriasis and psoriatic arthritis & $112(13)$ \\
\hline Others & $11(1)$ \\
\hline Missing & $3(0.3)$ \\
\hline \multicolumn{2}{|l|}{ Period of Humira use before switching, $n(\%)$} \\
\hline Less than 1 year & $204(23)$ \\
\hline More than $1-5$ years & $468(52)$ \\
\hline More than 5 years & $227(25)$ \\
\hline \multicolumn{2}{|l|}{ Patient-assessed disease activity prior to switch, $\mathrm{n}(\%)$} \\
\hline Very well controlled & $564(63)$ \\
\hline Controlled well & $225(25)$ \\
\hline Neither & $85(9)$ \\
\hline Not controlled & $12(1)$ \\
\hline Not controlled well at all & $10(1)$ \\
\hline Not applicable & $3(0.3)$ \\
\hline \multicolumn{2}{|l|}{ No of the new biosimilar injections before survey, $n$ (\%) } \\
\hline 1 & $92(10)$ \\
\hline $2-4$ & $318(35)$ \\
\hline $5-10$ & $372(41)$ \\
\hline More than 10 & $110(12)$ \\
\hline Missing & $7(0.8)$ \\
\hline \multicolumn{2}{|l|}{ Biosimilar, n (\%) } \\
\hline Imraldi & $561(62)$ \\
\hline Amgevita & $237(26)$ \\
\hline Hyrimoz & $56(6)$ \\
\hline Don't know/not sure & $45(5)$ \\
\hline
\end{tabular}

Values presented as $\mathrm{n}(\%)$.

Comparison of proportion of patients with worse perception or better perception of the new biosimilars between those expressing satisfaction and dissatisfaction in the switching process

The proportion of participants with worse perception of the new biosimilar in term of side effects, ease of using the injection device and managing their symptoms was lower in the patients satisfied with the written $(30 \%$ vs
$63 \%$, OR $0.15,95 \%$ CI 0.06 to $0.40 ; 40 \%$ vs $62 \%$, OR 0.35 , $95 \%$ CI 0.21 to $0.58 ; 28 \%$ vs $69.1 \%$, OR $0.11,95 \%$ CI 0.02 to 0.49 , respectively, all $p$ values are less than 0.05 ) (online supplemental table S2A) and verbal information (33\% vs $59 \%$, OR $0.15,95 \%$ CI 0.06 to $0.40 ; 42 \%$ vs $60 \%$, OR 0.45 , $95 \%$ CI 0.28 to $0.72 ; 32 \%$ vs $63 \%$, OR $0.20,95 \%$ CI 0.05 to 0.74 , respectively, all $\mathrm{p}$ values are less than 0.05) (online supplemental table S2B). Aside from that, respondents satisfied with the training for the new injection device reported fewer side effects ( $37 \%$ vs $60 \%$, OR $0.15,95 \%$ CI 0.06 to 0.41 ), less pain when injecting ( $70 \%$ vs $83 \%$, OR $0.19,95 \%$ CI 0.07 to 0.49 ) and reduced difficulty in use of the injection device after the switching process $(37 \%$ vs $66 \%$, OR $0.24,95 \%$ CI 0.15 to 0.40 ) (all $\mathrm{p}$ values are less than 0.05 ) (online supplemental table S2C).

\section{The benefits of informative communication and training in} use of a new injection device on patients' perception of a new biosimilar

Results of the final logistic regression model incorporating gender, self-reported disease activity and biosimilar brand are summarised in figure 2. The training in use of the new injection device was associated with a significant reduction in reported pain on administering the new biosimilar (OR $0.20,95 \%$ CI 0.07 to 0.55 ), reporting of side effects (OR $0.17,95 \%$ CI 0.06 to 0.47 ) and difficulty in using the device (OR $0.25,95 \%$ CI 0.15 to 0.41 ). Both satisfaction with written and verbal information about the switch to biosimilar provided by healthcare professionals was associated with fewer reported side effects (OR $0.13,95 \%$ CI 0.05 to 0.38 ) in respect of the written information and OR $0.15,95 \%$ CI 0.05 to 0.42 in respect of the verbal information). Furthermore, provision of information perceived as being satisfactory significantly reduced participants' complaints regarding use of the new biosimilar injection device (OR $0.38,95 \%$ CI 0.23 to 0.63 in respect of the written information and OR 0.45 , $95 \%$ CI 0.27 to 0.73 in respect of the verbal information) as well as in managing their self-reported disease activity as compared with originator ADA (OR $0.05,95 \%$ CI 0.004 to 0.57 and OR $0.15,95 \%$ CI 0.03 to 0.84 , respectively).

\section{DISCUSSION}

A recent systematic literature review of patient experience of switching biological treatment in patients with inflammatory arthritis or UC concluded that there is a sparsity of information regarding patient-reported experience of switching biologic treatment. ${ }^{7}$ The present survey, designed and initiated by the patient organisations, addresses this issue. Our findings unequivocally highlight the importance of provision of clear, co-produced information about the switch to biosimilar as well as appropriate training in the use of a new injection device. The clear consequence of this best practice is a reduction in patient reported side effects and injection related pain as well as improved ease of using the injection device and reduction in any negative perceptions regarding 
Table 2 Patient's experience in the process of switching

\begin{tabular}{|c|c|c|}
\hline Questions & Answers & $\begin{array}{l}\text { Participants } \\
(\mathrm{n}=899)\end{array}$ \\
\hline & & n (\%) \\
\hline \multirow{3}{*}{$\begin{array}{l}\text { 1. Have you shared any concerns you may have with your } \\
\text { consultant, specialist nurse, pharmacist or GP? }\end{array}$} & Yes & $388(43)$ \\
\hline & No & $423(47)$ \\
\hline & I didn't know I could & $87(10)$ \\
\hline & Yes, I was offered a switch to another treatment & $41(5)$ \\
\hline & No & $139(15)$ \\
\hline & Other free comment answers & $139(15)$ \\
\hline $\begin{array}{l}\text { 3. Did your consultant, specialist nurse or pharmacist seek } \\
\text { your consent to switch from Humira to a biosimilar? }\end{array}$ & Yes & $359(40)$ \\
\hline \multirow[t]{5}{*}{ 4. Overall, how satisfied are you with your new biosimilar? $\ddagger$} & Very satisfied & $74(8)$ \\
\hline & Satisfied & $177(20)$ \\
\hline & Neither & $132(15)$ \\
\hline & Somewhat satisfied & $202(23)$ \\
\hline & Not at all satisfied & $307(34)$ \\
\hline
\end{tabular}

*The patients who answered 'yes' in question 1 ( $n=388$ ) then proceeded to question 2. Four answers were missing in question 2. †Patients responding to Q2 had the opportunity to do so in the form of free comment. Findings from the free comments and open questions were not formally analysed as a part of the present work. ‡Seven answers were missing in question 4. GP, general practitioner.

symptom control with the new biosimilar. The survey findings also suggest that switching from ADA originator to biosimilar was often done with suboptimal communication. It is thought likely that learnings regarding the importance of good communication and training will be generalisable to switching between other biological originators and their biosimilars.

In order to be designated a biosimilar, a biological has to demonstrate very vigorous similarities to the originator in terms of a wide range of parameters including antigen binding and antibody function as well as providing clinical trial data that demonstrates equivalent efficacy in an indication for which the originator has been approved. ${ }^{8-13}$ From the perspective of healthcare economies, the potential savings generated by switching from originator to biosimilar products become considerable. For some healthcare systems for which biologics are purchased on the basis of a national or regional tender, such as
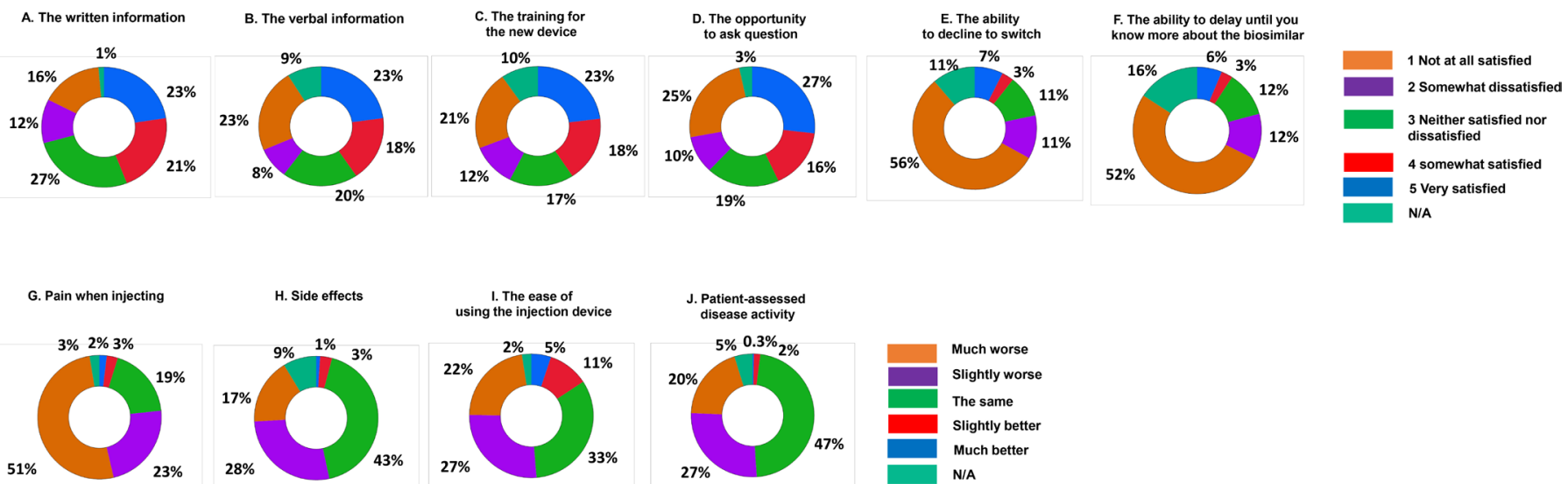

Figure 1 Donut charts illustrating the percentage of patients expressing different levels of satisfaction with various experiences associated with the switching process. N/A, not applicable. 


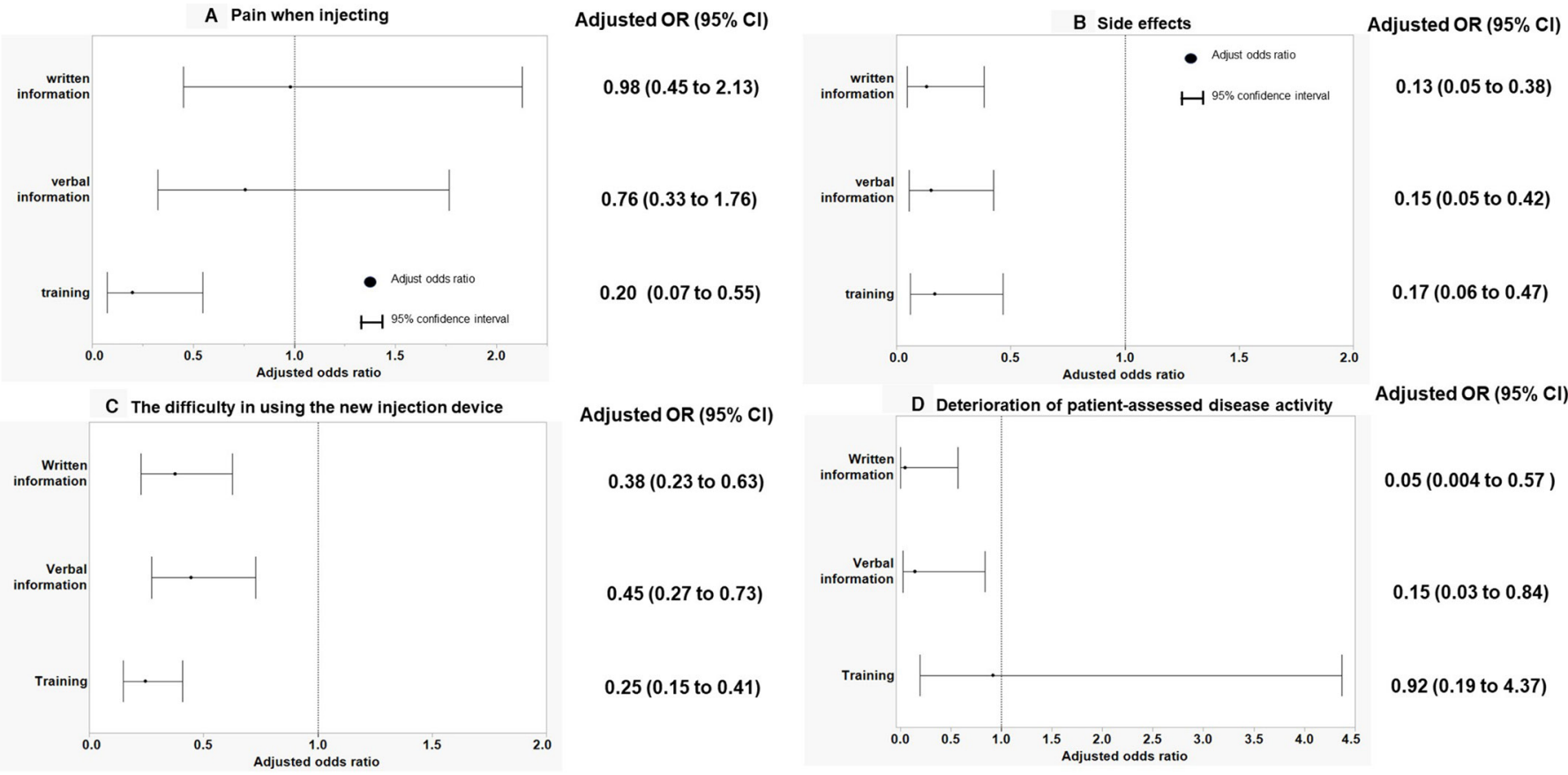

Figure 2 Adjusted ORs illustrating the influence of training and information from healthcare professionals in improving perception of the new biosimilar. Adjusted OR and $95 \%$ Cls were calculated by a multiple categorical logistic regression analysis using gender, self-reported disease activity and biosimilar brands as adjusted variables. Data to the left of the adjusted OR of 1 indicates a more favourable perception.

Norway $^{1415}$ or UK, for example, the originator drug price can also be lowered and compete in the tender process. While a more cost-effective biosimilar is very attractive for payers, it may appear much less so for patients who have responded well to an originator. They may initially be suspicious that they are being provided with a cheaper, and possibly less effective biologic alternative, purely to save money. While the complexity of clinical and biochemical evidence to support therapeutic equivalence between biosimilar and originator has been established prior to approval of a biosimilar, this is unlikely to be known to the lay public and patients without a comprehensible explanation. And even then, there may be differences in biologic formulations, as there were in the case of this switch from Humira to ADA biosimilar, such as citrated vs non citrated, and the injection device itself, which might give rise to differences in individual experiences of the tolerability and ease of use between an originator or biosimilar. Of note, $22 \%$ of respondents reported the ease of using the injection device to be much worse following the switch to biosimilar. Such practical difficulties may have deleterious consequences for medication adherence, either intentionally or non-intentionally. Ideally, it is important for a patient to be able to familiarise themselves with the new biosimilar delivery device prior to any switch in biological medication and to have the option to switch to a different device. ${ }^{16}$

A limitation in the survey design and invitation to participate is in the potential for selection bias among responders, therefore the high proportion of respondents (about two-thirds) expressing dissatisfaction with the switching process, may be an over-estimate of the wider population switched. Another limitation of the survey is that it was not designed or powered to assess any influence of the biologic formulation, such as citrated or non-citrated, on the switching experience.

So-called 'nocebo' responses have been previously documented, ${ }^{14}{ }^{17-21}$ and may be augmented by poor communication around the switching process. It is likely that nocebo responses might account for some of the reported dissatisfaction with the biosimilar in this large sample of survey respondents given that over a quarter were dissatisfied with either the verbal or written information communicated at the time of switch to ADA biosimilar. Our findings highlight the importance of healthcare professionals listening to their patients' experiences, taking them seriously and acting to investigate and resolve issues satisfactorily when they are reported. Even when taking into consideration that there may have been selection bias among respondents, this study illustrates that specialist physicians and healthcare providers still have much to do in order to communicate the likelihood of maintained benefits to the individual being switched, and also the potential for widening access to expensive drugs, as well as the economic benefits for the wider healthcare economy. In fact, many patients accept the switch to biosimilars on the false premise of altruistic thinking that more people with the same health condition will be prescribed an anti-TNF. Unfortunately, this was not possible while NICE guidance set the threshold of high disease activity for access to a biological anti-TNF for people with certain immune mediated inflammatory 
diseases, for example, $\mathrm{RA},{ }^{22} \mathrm{CD}^{23}$ and skin psoriasis. ${ }^{24}$ A challenge for the future will be whether the biosimilars might regarded as sufficiently cost-effective to allow access for patients with moderately active disease, as is the case in many other European health economies.

As more biosimilar drugs are anticipated in the future, the learnings from this study should help inform best practice with respect to the switching process, involving good communication with the patient and meaningful shared decision making, thereby facilitating best achievable outcomes. Means to facilitate this include preparation of clearly presented written material, produced with patient involvement, explaining the therapeutic and safety equivalence of biosimilars to their originators as well as the reasons that there are associated cost savings, and the benefits these might provide for the individual, the clinical service and to broader society. Furthermore, healthcare professionals involved in the switch process, including physicians, nurses, pharmacists and others, would benefit from training in use of different injection devices, provision of key verbal information and reassurance, and how to respond to frequently asked questions.

\section{Author affiliations}

${ }^{1}$ Nuffield Department of Orthopaedics, Rheumatology and Musculoskeletal

Sciences, Botnar Research Centre, University of Oxford, Oxford, UK

${ }^{2}$ Centre for Statistics in Medicine, Nuffield Department of Orthopaedics,

Rheumatology and Musculoskeletal Sciences, University of Oxford, Oxford, UK

${ }^{3}$ National Rheumatoid Arthritis Society (NRAS), Maidenhead, UK

${ }^{4}$ National Axial Spondyloarthritis Society, London, UK

${ }^{5}$ Crohn's \& Colitis, Hatfield, UK

${ }^{6}$ Psoriasis Association, Northampton, UK

Acknowledgements PCT thanks the National Institute of Health Research for their funding of The NIHR Biomedical Research Centre in Musculoskeletal Disease at Oxford University Hospitals NHS Foundation Trust and the University of Oxford.

Contributors PCT assumes overall responsibility for the work and all the reported data. $C J, A B, S D, S B$ and $H M$ designed the patient survey and were involved in data collection. PCT and KK wrote the first draft of the manuscript. KK, DP-A and PCT analysed the data. All authors contributed to discussion and interpretation of the results, critically reviewed the manuscript and approved the final version to be submitted.

Funding The authors have not declared a specific grant for this research from any funding agency in the public, commercial or not-for-profit sectors.

Competing interests DP-A reports grants and other from AMGEN, grants, nonfinancial support and other from UCB Biopharma, grants from Les Laboratoires Servier, outside the submitted work; and Janssen, on behalf of IMI-funded EHDEN and EMIF consortiums, and Synapse Management Partners have supported training programmes organised by DPA's department and open for external participants; CJ reports grants from Abbvie, grants from Amgen, grants from Biogen, grants from Eli Lilly, grants and other from Frensius Kabi, grants from Gilead, grants from Janssen, grants from Medac, grants from Pfizer, grants from Roche, grants from UCB, grants from BMS, grants from Sanofi, outside the submitted work; $A B$ reports grants from the following companies that are outside of and not related to the submitted paper: Abbvie, Amgen, Biogen, Eli Lilly, Fresenius Kabi, Gilead, Janssen, Medac, Pfizer, Roche, Sanofi, UCB, BMS; SD reports grants from AbbVie, grants from Biogen, grants from Eli Lilly, grants from Janssen-Cilag, grants from Novartis, grants from UCB, outside the submitted work; SB reports grants from Abbvie, grants from Amgen, grants from Celgene, grants from Janssen, grants from Gilead, grants from MSD, grants from Roche, grants from Sandoz, grants from Takeda, during the conduct of the study; HM reports grants from Abbvie, grants from Almirall, grants from Amgen, grants from Celgene, grants from Eli Lilly, grants from Janssen, grants from LEO Pharma, grants from UCB, outside the submitted work; PCT reports personal fees from AbbVie, personal fees from Biogen, personal fees from Celltrion, personal fees from Fresenius Kabi, outside the submitted work.

\section{Patient consent for publication Not applicable.}

Ethics approval This study describes a survey that was undertaken for the purposes of service evaluation and the data were collected and analysed anonymously. Ethics permission is not required for such work and this is the reason that no reference number has been provided. Participants gave informed consent to participate in the study before taking part.

Provenance and peer review Not commissioned; externally peer reviewed.

Data availability statement Data are available on reasonable request. Raw anonymous data are available to researchers on application to the patient organisations involved who will jointly assess any applications.

Supplemental material This content has been supplied by the author(s). It has not been vetted by BMJ Publishing Group Limited (BMJ) and may not have been peer-reviewed. Any opinions or recommendations discussed are solely those of the author(s) and are not endorsed by BMJ. BMJ disclaims all liability and responsibility arising from any reliance placed on the content. Where the content includes any translated material, BMJ does not warrant the accuracy and reliability of the translations (including but not limited to local regulations, clinical guidelines, terminology, drug names and drug dosages), and is not responsible for any error and/or omissions arising from translation and adaptation or otherwise.

Open access This is an open access article distributed in accordance with the Creative Commons Attribution Non Commercial (CC BY-NC 4.0) license, which permits others to distribute, remix, adapt, build upon this work non-commercially, and license their derivative works on different terms, provided the original work is properly cited, appropriate credit is given, any changes made indicated, and the use is non-commercial. See: http://creativecommons.org/licenses/by-nc/4.0/.

ORCID iDs

Daniel Prieto-Alhambra http://orcid.org/0000-0002-3950-6346

Peter C Taylor http://orcid.org/0000-0001-7766-6167

\section{REFERENCES}

1 Robinson J. The pharmaceutical Journal. Available: https:// pharmaceutical-journal.com/ article/feature/preparing-for-the-bigbiologic-switch

2 Medicines Diagnostics and Personalised Medicine Policy Team, National Medical Directorate, NHS England. Commissioning framework for biological medicines (including biosimilar medicines), 2017. Available: https://www.england.nhs.uk/wp-content/uploads/ 2017/09/biosimilar-medicines-commissioning-framework.pdf [Accessed 29 Apr 2020].

3 Medicines and Diagnostics Policy Unit, NHS England. Commissioning intentions: adalimumab, 2018. Available: https:// www.sps.nhs.uk/wp-content/uploads/2018/09/20180925Contractual-Commissioning-Intentions-Adalimumab corporatetemplate.pdf [Accessed 29 Apr 2020]

4 van Overbeeke E, De Beleyr B, de Hoon J, et al. Perception of Originator biologics and biosimilars: a survey among Belgian rheumatoid arthritis patients and rheumatologists. BioDrugs 2017;31:447-59.

5 Aladul MI, Fitzpatrick RW, Chapman SR. Patients' understanding and attitudes towards infliximab and etanercept biosimilars: result of a UK web-based survey. BioDrugs 2017;31:439-46.

6 Bridges SL, White DW, Worthing AB, et al. The science behind biosimilars: entering a new era of biologic therapy. Arthritis Rheumatol 2018;70:334-44.

7 Luttropp K, Dalén J, Svedbom A, et al. Real-World Patient Experience of Switching Biologic Treatment in Inflammatory Arthritis and Ulcerative Colitis - A Systematic Literature Review. Patient Prefer Adherence 2020;14:309-20.

8 Edwards CJ, Monnet J, Ullmann M, et al. Safety of adalimumab biosimilar MSB11022 (acetate-buffered formulation) in patients with moderately-to-severely active rheumatoid arthritis. Clin Rheumatol 2019;38:3381-90.

9 Cohen SB, Czeloth N, Lee E, et al. Long-Term safety, efficacy, and immunogenicity of adalimumab biosimilar BI 695501 and adalimumab reference product in patients with moderatelyto-severely active rheumatoid arthritis: results from a phase 3B extension study (VOLTAIRE-RAext). Expert Opin Biol Ther 2019;19:1097-105. 
10 Cohen S, Pablos JL, Pavelka K, et al. An open-label extension study to demonstrate long-term safety and efficacy of ABP 501 in patients with rheumatoid arthritis. Arthritis Res Ther 2019;21:84.

11 Weinblatt ME, Baranauskaite A, Dokoupilova E, et al. Switching from reference adalimumab to SB5 (adalimumab Biosimilar) in patients with rheumatoid arthritis: Fifty-Two-Week phase III randomized study results. Arthritis Rheumatol 2018;70:832-40.

12 Cohen SB, Alonso-Ruiz A, Klimiuk PA, et al. Similar efficacy, safety and immunogenicity of adalimumab biosimilar BI 695501 and Humira reference product in patients with moderately to severely active rheumatoid arthritis: results from the phase III randomised VOLTAIRE-RA equivalence study. Ann Rheum Dis 2018;77:914-21.

13 Fleischmann RM, Alten R, Pileckyte M, et al. A comparative clinical study of PF-06410293, a candidate adalimumab biosimilar, and adalimumab reference product (Humira $\otimes)$ in the treatment of active rheumatoid arthritis. Arthritis Res Ther 2018;20:178.

14 Sigaux J, Semerano L, Boissier M-C. Switch to a biosimilar: whatever the cost? Joint Bone Spine 2018;85:651-4.

15 Jørgensen KK, Olsen IC, Goll GL, et al. Switching from originator infliximab to biosimilar CT-P13 compared with maintained treatment with originator infliximab (NOR-SWITCH): a 52week, randomised, double-blind, non-inferiority trial. Lancet 2017;389:2304-16.

16 Thorneloe RJ, Griffiths CEM, Emsley R, et al. Intentional and unintentional medication Non-Adherence in psoriasis: the role of patients' medication beliefs and habit strength. J Invest Dermatol 2018;138:785-94.
17 Neame R, Hammond A. Beliefs about medications: a questionnaire survey of people with rheumatoid arthritis. Rheumatology 2005;44:762-7.

18 Boone NW, Liu L, Romberg-Camps MJ, et al. The nocebo effect challenges the non-medical infliximab switch in practice. Eur J Clin Pharmacol 2018;74:655-61.

19 Fleischmann R, Jairath V, Mysler E, et al. Nonmedical switching from originators to biosimilars: does the nocebo effect explain treatment failures and adverse events in rheumatology and gastroenterology? Rheumatol Ther 2020;7:35-64.

20 Germain V, Scherlinger M, Barnetche T, et al. Long-Term follow-up after switching from originator infliximab to its biosimilar CT-P13: the weight of nocebo effect. Ann Rheum Dis 2020;79:e11.

21 Kravvariti E, Kitas GD, Mitsikostas DD, et al. Nocebos in rheumatology: emerging concepts and their implications for clinical practice. Nat Rev Rheumatol 2018;14:727-40.

22 National Institute for Health and Care Excellence. Adalimumab, etanercept, infliximab, certolizumab pegol, golimumab, tocilizumab and abatacept for rheumatoid arthritis not previously treated with DMARDs or after conventional DMARDs only have failed. Technology appraisal guidance (TA375) 26 January 2016. Available: https://www. nice.org.uk/guidance/ta375/chapter/1-Recommendations

23 Infliximab and adalimumab for the treatment of Crohn's disease. Technology appraisal guidance [TA187]. Available: https://www.nice. org.uk/guidance/ta187 [Accessed 19 May 2010].

24 Adalimumab for the treatment of adults with psoriasis. Technology appraisal guidance [TA146], 2008. Available: https://www.nice.org.uk/ guidance/ta146/chapter/1-Guidance 